\title{
PARTICLE SIZE DISTRIBUTION OF A WASTE SAND FROM A WASTE WATER TREATMENT PLANT WITH USE OF ROSIN-RAMMLER AND GATES-GAUDIN- SCHUMANN MATHEMATICAL MODEL
}

\author{
T. Vítěz, P. Travníček
}

Received: October 12, 2010

\begin{abstract}
VÍTĚZ, T., TRÁVNÍČEK, P.: Particle size distribution of a waste sand from a waste water treatment plant with use of Rosin-Rammler and Gates-Gaudin-Schumann mathematical model. Acta univ. agric. et silvic. Mendel. Brun., 2011, LIX, No. 3, pp. 197-202

Particle size distribution of the sample of waste sand from waste water treatment plant have been determined with two commonly used methods of mathematical models by Rosin-Rammler (RR model) and by Gates-Gaudin-Schuhmann (GGS model). On the basis of network analysis distribution function, $F(d)$ (mass fraction) and density function, $f(d)$ (number of particles captured between two screens) have been obtained. Experimental data have been evaluated using the RR model and GGS model, both models have been compared. Better results were achieved with GGS model, which leads to a more accurate separation of the different particle sizes in order to obtain a better industrial profit of the material.
\end{abstract}

waste sand, particle size distributions, waste water treatment plant, modelling

Particle size is one of the most important physical properties of solids, which is used in many fields of human activity, such as construction, waste management, metallurgy, fuel fabrication, etc. Waste sand is a solid waste product from a water purification process. For these materials it is necessary to specify the basic physical parameters, one of the most important property is a particle size distribution. Determination of particle size of waste sand can help us for better utilization of this material.

A number of methods designed to determine particle size (sieving, microscopy, etc.) has been described in the literature (Dierickx et al., 2000; Macı'as-Garcı'a et al., 2004). Using different methods to determine particle size distribution can get quite different results (Rosin and Rammler, 1933; Ramakrishnan, 1994). The kind of method which will be used depends mainly on the characteristics of the analyzed material.

Result of particle size distribution analysis can be expressed in different forms, according to the particle diameter indicating by nominal mesh sizes, or by particle size distribution, in grams, in percentage by weight of each fraction (differential distribution, as the cumulative percentage of sizes below a given value, undersize, and as the cumulative percentage of size above a given value, oversize) (Ballester et al., 2000).

The goal of this work is to obtain a distribution function $F(d)$ (mass fraction) and density function $f(d)$ (number of particles captured between two screens) of the sample of waste sand using RR and GGS mathematical models applied to data obtained by network analysis (Macı'as-Garcı'a et al., 2003). 


\section{MATERIAL AND METHODS}

Samples of waste sand were collected from the sand trap in the waste water treatment plant. The collection of samples was based on TNI CEN/TR No. 10381-6. 1998: Soil quality Sampling-Part 6. On the day of collection the samples have been transported to the laboratory. Samples were rid of organic material and in the electric furnace samples were dried at $105^{\circ} \mathrm{C}$. After the waste sand particles were separated into different particle sizes using a $200 \mathrm{~mm}$ diameter sifting column whose internal diameters correspond to those set out in the ČSN EN 933-1. This column was placed on a vibrating table at 150 vibrations per minute for $30 \mathrm{~min}$. The resulting values allow one to obtain the experimental particle size distribution curves. These represent the percentages by weight versus particle size. For precise weighting analytical laboratory balances Radwag AS 220/X, with readability to $0.0001 \mathrm{~g}$ has been used.

The RR model distribution function has been used to describe the particle size distribution of powders of various types and sizes. The function is particularly suited to represent powders made by grinding, milling, and crushing operations. The general expression of the RR model is:

$F(d)=1-\exp \left[-\left(\frac{d}{l}\right)^{m}\right]$,

where:

$F(d)$ distribution function

d.... particle size [mm] l.......mean particle size [mm]

$m$.....measure of the spread of particle sizes.

Parameters $l$ and $m$ are adjustable parameters characteristic of the distribution. Equation (1) may be rewritten as:

$\ln \{-\ln [1-F(d)]\}=m \times \ln d-m \times \ln l$.

If we use RR mathematical model for particle size distribution, a plot of the first term of equation (2), versus natural logarithm $d$ will result a straight line of slope $m$ if the behaviour of the material fits the RR model. The application of the function to a specific distribution calculation of its parameters is often performed by linear regression data, expressed as $\ln \{$ - $\ln [1-F(d)]\}$, versus $\ln d$, indicating the applicability of RR model for particle size distribution curve. For the regression analysis is also frequently used method of least squares, using which we can convert curves to data points. The correlation coefficient is used as a parameter indicating the relevance of the measured data set.

The density function in RR mathematics model will be:

$f(d)=\frac{m}{l^{m}} \times d^{m-1} \exp \left[-\left(\frac{d}{l}\right)^{m}\right]$.

Another popular model for determining particle size distribution is the GGS model, which is for simplicity and clarity used in industry since 1940 and is defined as:

$F(d)=\left[\frac{d}{d_{\max }}\right]^{m}$,

I: Particle size distribution of waste sand

\begin{tabular}{cccccc}
\hline Particle size & Mesh size & Fraction & Fraction & Cumulative weight under & Cumulative weight over \\
\hline$[\mathrm{mm}]$ & {$[\mathrm{mm}]$} & {$[\mathrm{g}]$} & {$[-]$} & {$[-]$} & {$[-]$} \\
\hline$<0.63$ & 0.63 & 3.1749 & 0.018103 & 0.981896 & 0.018104 \\
$0.63-0.125$ & 0.125 & 0.4801 & 0.002738 & 0.979159 & 0.020841 \\
$0.125-0.25$ & 0.25 & 54.3858 & 0.310118 & 0.669041 & 0.330959 \\
$0.25-0.5$ & 0.5 & 83.1959 & 0.474398 & 0.194642 & 0.805358 \\
$0.5-1$ & 1 & 28.9778 & 0.165237 & 0.029406 & 0.970594 \\
$1-2$ & 2 & 3.1612 & 0.018026 & 0.011380 & 0.988620 \\
\hline
\end{tabular}

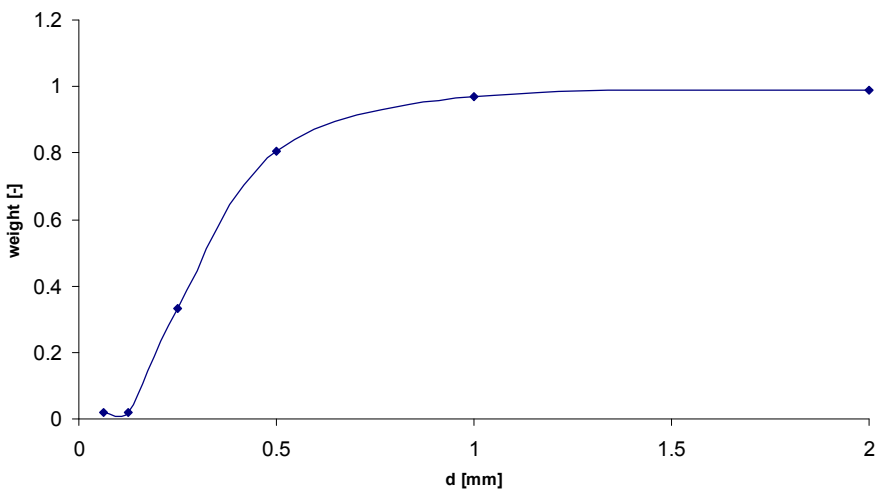

1: Particle size distribution obtained by network analysis 


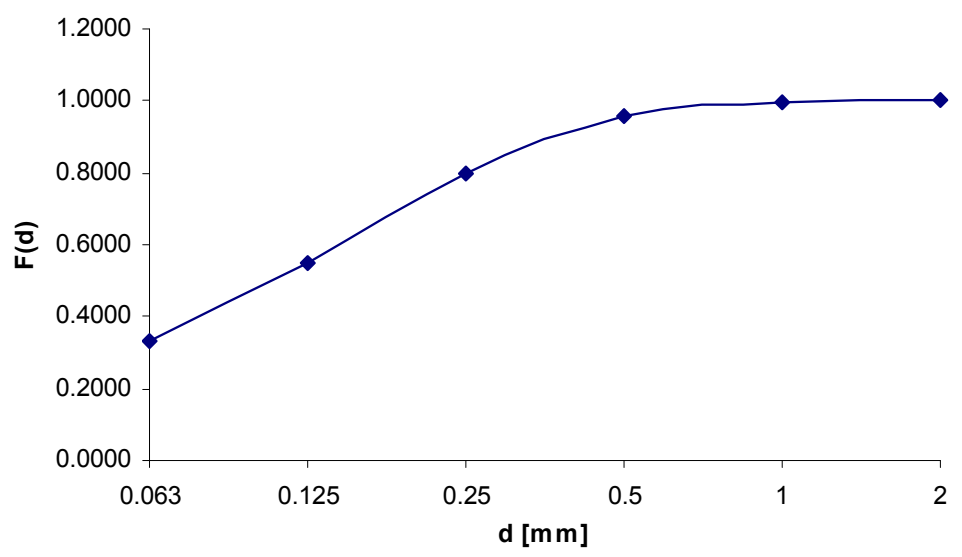

2: Plot of the distribution function versus particle size

where:

$F(d)$ the fraction of the sample finer than size $d$ $d$.... particle diameter $[\mathrm{mm}]$

$d_{\max }$. maximum particle diameter of the distribution (size modulus) [mm]

$m$..... distribution module.

If we plot logarithm of $F(d)$ versus the logarithm of particle size $d$, we get a straight line with a slope parameter $m$, the curve can be describe by the mathematical expression:

$\log F(d)=m \times \log d-m \times \ln d_{\max }$
If the particle size distribution curve fits the GGS model, plot of the logarithm of the distribution function versus the logarithm of the particle diameter of the tested material is shown as a straight line. The density function in this model can be written as:

$f(d)=\frac{m \times d^{m-1}}{d_{\max }^{m}}$.

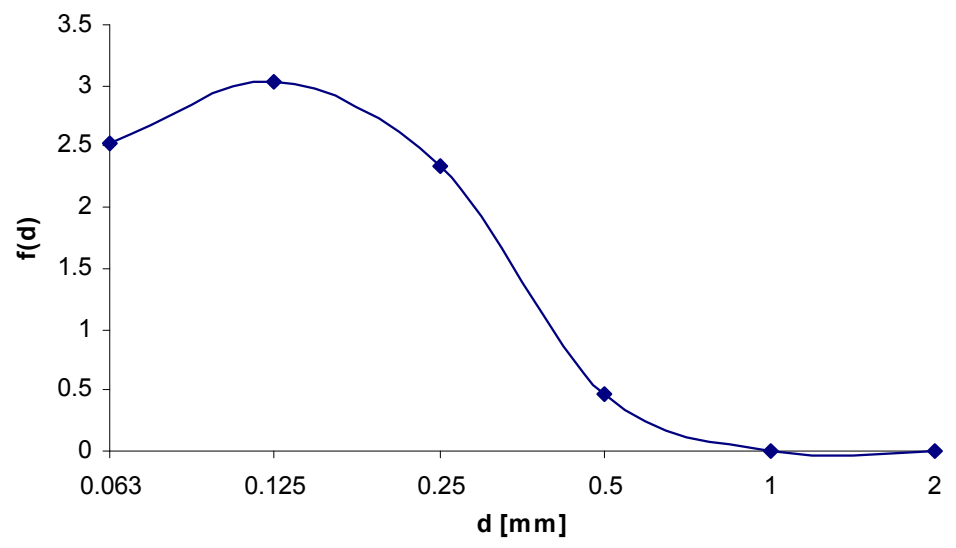

3: Plot of the density function versus particle size

II: Fit of tested material to the RR a GGS model

\begin{tabular}{cccccccc}
\hline Cumulative weight under sieve & $\boldsymbol{F}(\boldsymbol{d})$ & $\mathbf{d}$ & $\mathbf{f}(\mathbf{d})$ & $\log \mathbf{F}(\mathbf{d})$ & $\log \mathbf{d}$ & $\ln \{-\ln [\mathbf{l}-\boldsymbol{F}(\boldsymbol{d})]\}$ & $\ln \mathbf{d}$ \\
\hline$[-]$ & {$[-]$} & {$[\mathbf{m m}]$} & {$[-]$} & {$[-]$} & {$[-]$} & {$[-]$} & {$[-]$} \\
\hline 0.018104 & 0.3303 & 0.63 & 2.520585 & -0.4811 & -1.2007 & -0.91396 & -2.7646 \\
0.020841 & 0.5486 & 0.125 & 3.031512 & -0.2607 & -0.9031 & -0.22878 & -2.0794 \\
0.330959 & 0.7963 & 0.25 & 2.341147 & -0.0989 & -0.6021 & 0.46436 & -1.3863 \\
0.805358 & 0.9585 & 0.5 & 0.471303 & -0.0184 & -0.3010 & 1.1575 & -0.6931 \\
0.970594 & 0.9983 & 1 & 0.001653 & -0.0007 & 0.0000 & 1.8506 & 0.0000 \\
0.988620 & 1.0000 & 2 & $2.91 E-11$ & 0.0000 & 0.3010 & 2.54380 & 0.6931 \\
\hline
\end{tabular}




\section{RESULTS AND DISCUSSION}

The values of the weights of different particle sizes of waste sand mixture obtained by network analysis are shown in Tab. 1, together with the cumulative percentage of weight. Fig. 1 shows the corresponding particle size distribution curve. Fig. 2 shows the distribution function $F(d)$, which was obtained by fitting of measured data of Fig. 1 to Eq. 1. This function shows the different fractions of a waste sand of by volume, weight or number of particles. Value of the function at a given point is the ratio of the number of the particles (mass or volume), which is lower than a given size.

Finally area under the curve between two sizes of particles (eg., $d_{1}$ and $d_{2}$ ) is the number of particles (expressed as particle of mass or volume), whose averages are included in this interval:

$F\left(d_{2}\right)-F\left(d_{1}\right)=\int_{d_{1}}^{d_{2}} f(d) d(d)$.
The final inclination of distribution function (depending on the diameter of particles, $d$ ), at each point indicates the density function $f(d)$, which is defined by Eq. 3 and shown in Fig. 3. This function represents the differential curve, which corresponds to the proportion of particles of a certain size. Curve analysis of waste sand is shown in Fig. 1, is similar to many other materials. Curve in the Fig. 2 and Fig. 3 is quite unusual (Macl'asGarcl'a et al., 2004). To evaluate the measured data in Tab. I, two above described models have been used. The results of solution of the two models are shown in Tab. II, Fig. 4 and 5 shows the compliance of the test sample of waste sand with RR and GGS model. From the observation of the two figures and the corresponding linear correlation coefficient, one deduces that the RR model provides a better fit to the experimental GGS curve than RR does. However, when testing other materials GGS model can be better fit to the experimental PSD curve. (Vítěz et al., 2010).

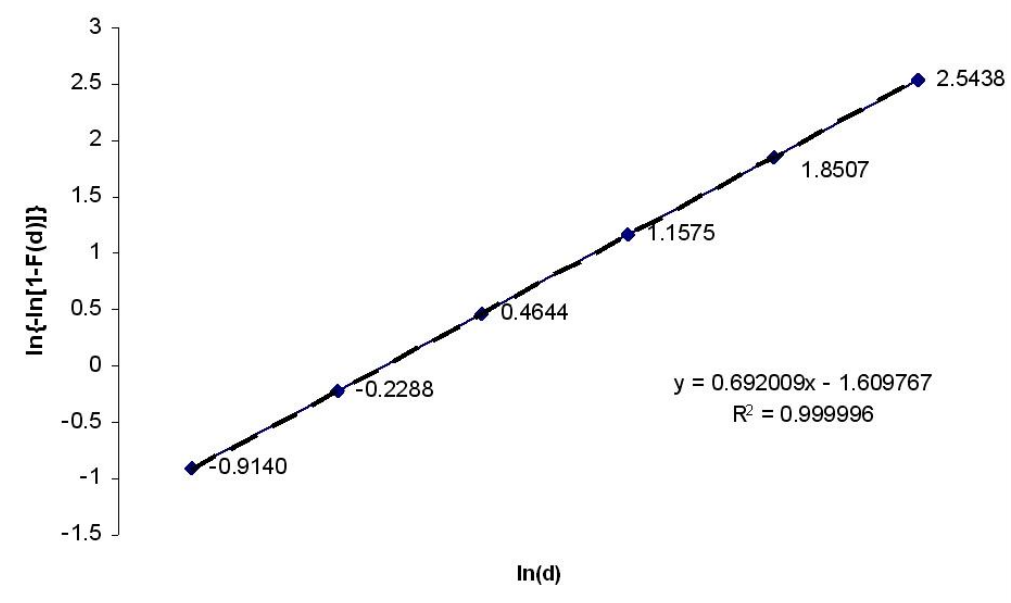

4: Fit to RR model

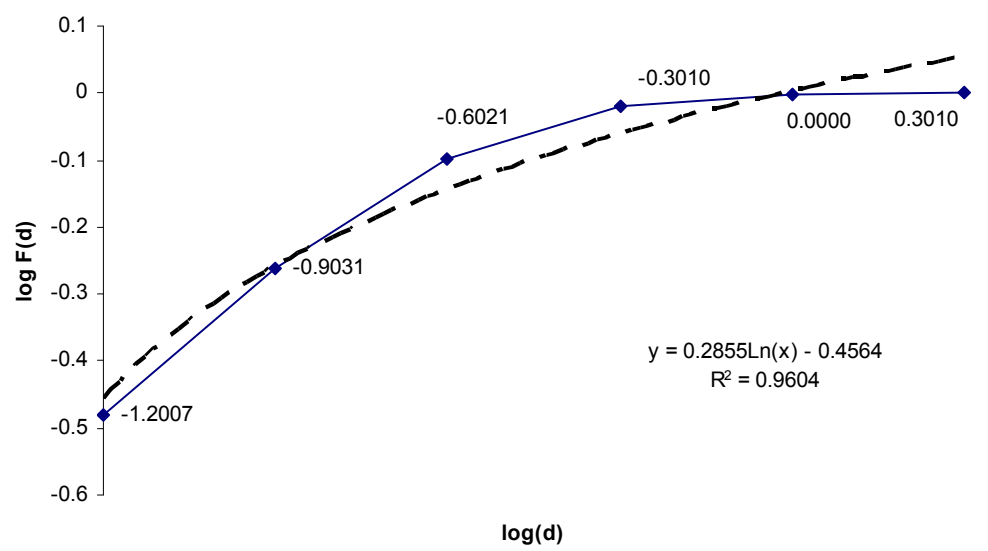

5: Fit to GGS model 


\section{SUMMARY}

Particle size is probably the most important single physical characteristic of solids. In addition, it may be easily determined by using low-cost methods. A correct determination of particle size of a waste sand is necessary prior its industrial utilization in different fields, such as wastewater treatment. Two mathematical models widely used to study the PSD of solids have been applied to waste sand. The RR model provides excellent results when applied to the sample here studied, which leads to a more accurate separation of the different particle sizes to a better industrial profit of the material. On the other hand, the GGS model does not properly fit the experimental data. Nevertheless, further investigations are being carried out for some other materials with hopeful results.

\section{REFERENCES}

BALLESTER, A., VERDEJA, L. F., SANCHO, J. P., (2000): Metalurgia Extrativa, Vol. 1.

DIERICKX, D., BASU, B., VLEUGELS, J., VAN DER BIEST, O., 2000: Statistical extreme value modeling of particle size distributions, Mater Charact, 45: 61-70.

MACI'AS-GARCI'A, A., CUERDA-CORRERA, EDUARDO M., DI'AZ-DIEZ, M. A., 2004: Application of the Rosin-Rammler and Gates-Gaudin-Schuhmann models to the particle size distribution analysis of agglomerated cork, Materials Characterization, 52: 159-164.

MACI'AS-GARCI'A, A., DI'AZ-PARRALEJO, A., DI'AZ-DIEZ, M. A., DE LA ROSA BLANCO, P. GO'MEZ, SERRANO, V., 2003: Bending strength of black and composite agglomerates of cork. Mater Lett: 4004-8.

RAMAKRISHNAN, K., N., 1994: Investigation of the effect of powder particle size distribution on the powder microstructure and mechanical properties of consolidated material made from a Rapidly solidified Al, Fe, Ce alloy powder: Part I. Powder microstructure. Mater Charact, 33: 11928.

ROSIN, P., RAMMLER, E., 1933: The Laws Governing the Fineness of Powdered Coal. Journal of the Institute of Fuel, 7: 29-36.

VÍTĚZ, T., TRÁVNÍČEK, P., 2010: Particle size distribution of sawdust and wood shavings mixtures. Research in agricultural engineering, 56: 154-158.

\section{Address}

Ing. Tomáš Vítěz, Ph.D., Ing. Petr Trávníček, Ústav zemědělské, potravinářské a environmentální techniky, Mendelova univerzita v Brně, Zemědělská 1, 61300 Brno, Česká republika, e-mail: vitez@mendelu.cz 
